\title{
Exploration on Biochemistry Teaching Reform for Food Major under MOOC Environment
}

\author{
Feng Ding* \\ College of Food Science and Engineering \\ Qilu University of Technology (Shandong Academy of \\ Sciences) \\ Jinan, China \\ bio_ding@126.com
}

\author{
Xingli Zhang \\ College of Food Science and Engineering \\ Qilu University of Technology (Shandong Academy of \\ Sciences) \\ Jinan, China
}

\begin{abstract}
The rise of MOOC worldwide has brought the unprecedented shocks and challenges to the traditional class teaching. Although the content of biochemistry courses in the MOOC resource of the universities at home and abroad has continued to increase, the systematic analys is and studies for the application practice of these courses are still insufficient. This paper performs analysis and summary on the problems in the of implementing the MOOC for the food biochemistry course e.g. the non-reconciliation of teaching programme in the establishment of MOOC teaching platform, face-to-face course and the organization of communication channels, MOOC development and application capacity of teachers are insufficient, the organization of course content is short of interest, the study efficiency of face-to-face course is low, the communication channels of course are not smooth and the form of class notes is too simple, as well as puts forwards the corresponding advises to provide the references for promoting the biochemistry teaching reform of food major.
\end{abstract}

Keywords—MOOC; food major; biochemistry; teaching reform

MOOC refers to the teaching process that is responsible by the lecturer and performs several elements e.g. teaching, excising, testing and interaction etc. [1] Biochemistry is the basic compulsory course for the majors relating to Food and Bioengineering in universities. Currently the studies on the application of MOOC in biochemistry teaching and reform are still in the initial stage[2]. Applying MOOC to the biochemistry teaching can reduce the repeated physical class teaching work for teachers, which enables the teachers to put more efforts on studying the teaching methods and research work, so as to better improve the teaching quality. Along with the development of information technology, more and more courses have established the combined online and offline types of courses. However, the phenomena e.g. the quality of courses are uneven, the studying initiative of students is not high and the teaching quality is reduces instead of improving are still existing. This paper studies the issues need to pay attention when such new teaching method MOOC is penetrating and promoting biochemistry teaching, and it is expected to provide the ideas for pushing the teaching reform of biochemistry.

\section{Construction of MOOC Teaching Platform}

First of all, reform the teaching programme mainly based on the traditional indoctrination teaching from class teachers.
The teaching programme is the baton for teachers to perform carry out teaching activities. Put the key and difficult content of courses in class via lecturing, and that simple and easy-tounderstand content are arranged as the self-study of students. As for the aspect of course assessment, the traditional biochemistry teaching programme has regulated that the composition of students' performance is $30 \%$ for usual performance and $70 \%$ for final examinations respectively. In which, the usual performance includes class attendance performance, class performance and usual homework. Due to the reduction in teaching hours and increase in teaching task in recent years, a number of teachers are applying the indoctrinatory teaching in order to catch up with the teaching process, which is short of the interaction and communication with students, or there are only random questions, the phenomenon of Plagiarism between students is severe, it is difficult to reflect the usual study of students. The study initiatives of students are low with a rushed preparation prior to examinations, and the students will not study after failing the examinations. Under the MOOC teaching environment, it enables to change the performance proportion of students to $50 \%$ for usual performance and final examinations respectively. In which, the usual performance includes the study process of teaching videos, the results of chapter tests, the performance of course forum and the performance in class. Due to the teaching videos and other teaching materials have been uploaded to the teaching platform, the students can review the key and difficult content of courses repeatedly, and consult the lecturers for any part they don't understand, which provides basic conditions for students to put efforts on the usual study. The teaching video is set up the pop-up window of questions, which can only continue to play after the students answer the questions. This will prevent the students refreshing the progress of video without watching it. Each chapter sets up the chapter tests with limitations to the answering time, and the tests can't be changed after submission, so as to test the studying effect of each chapter for students. Due to the increase in the proportion of usual performance, the students will attach more importance to the usual study.

Secondly, the front-line teaches undertaking the teaching task of universities should adapt to studying and grasping the technical methods and approaches on teaching design, development and application of MOOC. Currently there are commercialized MOOC production companies that can 
produce the MOOC courses in China. However, along with the rapid development of biochemistry, the new theories and technologies are appearing, the individual teaching levels of teachers are increasing, it is required to keep improving the course combined with the actual application of MOOC. Currently the steps and requirements of MOOC construction are excessively complex, the operation and maintenance of courses require a number of persons, which leads to the low efficiency of optimizing and updating of courses. The courses platform can only pay more attention to the studying experience instead of the convenience and effectiveness of managing courses for the teachers. Enabling the teachers to take the data on students studying behaviors and feedback obtained in the course of teaching as the teaching references is able to generate the positive promotion for the teaching of teachers. All of these require that the teachers should have certain abilities of MOOC design, development and application. It is necessary to learn how to establish the individual teaching resource base and online teaching supporting environment, get familiar with the production tools of micro-courses, realize the best presenting effects of graphic design and grasp the production techniques of micro-courses etc.

The teachers should establish their own courses recourse base. On one hand, many teachers will complain that a number of students don't make good use of the information technology, mobile phone or computer, and they will waste time in playing games and watching videos once they have internet. Part of the reason is that the teachers contribute less resources in this internet society, the students can't see their teachers in mobile phone or internet too often, the teachers don't design the appropriate studying resources used in the internet environment for students. On the other hand, the more sharing, opener and easier-to-obtain the high-quality resources on the internet is, and the harder the teachers to find their own position. A number of teachers are not used to implementing teaching in such environment and they can't make the attractive teaching content for students. When the teachers are searching their own teaching resources, they should have their own clear and familiar content. Therefore, the teachers need to create one such place belonged to themselves, they can access to this place for searching any materials relating to the teaching of this course. If it doesn't have the content that the teachers need, they will try to complement and optimize it. As the platform of resource base, it can be its own website, but also the free network disk, blog, Official Accounts or course platform on the internet. I recommend the teachers to select WeChat Official Accounts or course platform (e.g. Netease cloud class etc.) as the platform resources, using course to manage resources, using the concept of course to create their own resource base. The purpose of creating resource base is not the subscription or the number of visitors for browsing, the most important is to accumulate materials for their own teaching, and enables them to leave something own after teaching each time.

Thirdly, the course content should be developed elaborately and try to enhance the studying initiative of students. Due to this information explosion, there are fewer students who can watch one same video for long time. Therefore, as for the content of video, the teachers shall focus on producing the key and difficult points of courses in the form of "micro-course".
The video shall not be too long and it will be easy for students to accept with better effect ${ }^{[3]}$. The concepts and phenomena of biochemistry always exist in the micro-world. The students are unable to observe them directly; therefore, it makes the students feel bored and abstract. Present all reaction inside body in the dynamic form. Producing animation video is to present these complex reactions to the students in intuitional, clear, visual and vivid manners, which can promote the students to better understand such unintelligible knowledge and obtain the good studying effects. Take the fat metabolism unit in the biochemistry for example; the key content of this chapter is $\beta$ - oxidation, acetone bodies, and fatty acid synthesis and metabolism regulation. The fat digestion and absorption play great role in arousing the interest of students as the beginning part of this chapter. How to select the knowledge point from is to produce the teaching video? As the interest arouser of "appetizer", it is certain to select the content that can be combined with the actual life or arouse interest of students easily as the design target. Therefore, selecting the knowledge points in beginning three units of this chapter: the digestion and absorption of exogenous fatty acids, degradation of endogenous fatty acids, excitation and transport of fatty acids, as well as integrate the hot topic "fat control" into the entire above knowledge points for producing the teaching videos. The titles of original knowledge points are obscure and boring, it is necessary to redesign one resounding name for each knowledge point in order to catch the interest of students. It enables the students to generate the studying interest once they see the names, so as to take initiatives to preview, consult material and study deeply. Change the names of knowledge points for three micro-courses "the digestion and absorption of exogenous fatty acids, degradation of endogenous fatty acids, excitation and transport of fatty acids" to "how is the taken fatty meat not absorbed? How to lose weight on body? Is the L-carnitine really effective?”. The titles for these micro-courses are close to life and they are the issues regarding the ways of losing weight, health care products of losing weight greatly concerned by the students and society. Connecting the basic metabolism of biochemistry with the social life increases the practicalness and interest.

\section{ORganization And ARRAngement of FACE-TO-FACE COURSE AND COURSE COMMUNICATION CHANNELS}

The teaching method MOOC itself has certain weaknesses. It lacks the pleasant atmosphere possibly appeared in traditional classes, the atmosphere group listening and mutual infection, as well as the problems and wonderfulness temporarily generated in traditional classes. Therefore, it is a really important issue on how to organize the face-to-face class. The face-to-face class is mainly used to reinforce the key and difficult content of courses, organize the students to discuss and communicate, as well as take the class performance of students as one part of usual performance for scoring as quantization. The psychological studies have shown that people's attention is usually between 25 to $30 \mathrm{~min}^{[5]}$. As for a 45-minute class, the students are easy to slack, get tired, distract during the latter time. Therefore, the teachers always make use of the early half of class time for teaching the key and difficult content of course, and the latter part of class for students to discuss and speak. It is able to fixedly divide the 
students into several discussion teams and the discussion can be carried out by team. Finally each team will entrust one representative to speak, and the score is given by taking team as the unit. It provides certain operability for scoring the class performance. The discussion topics can be set as the cases and hot topics combined with list ${ }^{[6]}$. For example, why adding the enzyme in washing powder? What enzyme is added? When teaching protein $\alpha$-spiral, they can discuss the molecular mechanism of perming hairs. After explosion of melamine case, allow the students to discuss by using what quantitative method of protein to cause the protein level of melamine milk to reach standards. As for the discussion topics need to consult more materials can be arranged in advance, the students can consult documents after class to improve the discussion efficiency in the class. The active and dynamic discussion will enable the distracted and tired students to be excited again.

\section{DIVERSIFIED FormS OF ClASS Notes}

In traditional classes, the students should take notes on the notebook or books while listening to the lecture of teacher. Although it has the advantages of strengthening memories, saving the essence after removing the roughness, as well as training the students' ability to grasp key points etc. However, it is impossible for students to record on papers while teachers are lecturing the pictures and videos presented on the media due to the content of biochemistry is abstract and complex. They are unable to produce the systematical notes. If they review the media or videos after class, which not only wastes time but also there is no lecture of teachers. Meanwhile, the students can't follow up the rapid lecturing pace of teaching in traditional way when they are taking notes while listening to teachers' lecture. There are a number of APP in mobile phone for taking notes, including the manual input, Pinyin input, voice input, video recording, audio or pictures. A number of recording methods not only improve the efficiency of taking note for students, but also record the visual vivid media content together with the lecture of teachers to facilitate the understanding of complex and abstract knowledge points in biochemistry. For example, as for the students like WeChat, it is recommended to take note by WeChat. First of all, it is easy to use WeChat for taking note, and it is more methodical compared with recording only by shooting. It is unnecessary to download or install. After opening the collection of WeChat, click "+" on the upper right corner and it will record. There are five basic functions for WeChat taking note: (1) Words: support keyboard input and support the voice input; (2) Picture: support the pictures saved in mobile phone and the real-time shooting; (3) Voice: support real-time recording and replace the recording pen; (4) Location: provide the function of fast inserting geographic position; (5) Task: provide task list and other forms of list, and it is easy to streamline afterwards compared with the simple recording. Moreover, WeChat note recording can be synchronized to the server. The notes recorded by the collection of $\mathrm{PC}$ WeChat can be further streamlined for its content, which is easy to process, share and search.

Due to applying the combined online and offline teaching, the meeting times between students and teachers are reduced. However, within the limited teaching time, the teachers on one hand need to reinforce the key and difficult content of teaching, and on the other hand to organize the class discussion. It is hard for the students to discuss with teachers on the problems occurred by individual student in the course of studying. Meanwhile, the teachers should remind the students with their online study behind the progress in a timely manner, which requires the communication between teachers and students to be guaranteed. Firstly of all, MOOC studying platform adds the function of making statistics for studying progress of each student. The teachers can send group messages through studying system for reminding those students who are behind studying progress. Secondly, it is able to build communication group of course on WeChat platform, which is mainly used to deal with the routine work in the course of teaching courses, e.g. the technical problems of students using the online platform, the time of face-to-face class, progress arrangement, homework arrangement and the specific requirements etc. while facilitate the sharing of excellent teaching resources on WeChat official accounts. Thirdly, the online platform sets up courses teaching forum that mainly solves the key and difficult content encountered in the course of studying for students, Q\&A of homework. Meanwhile, the teachers can share the science development relating to biochemistry, scientist stories and life knowledge etc., as well as encourage the students to share the papers relating to courses that they have read from internet or other sources here. The students with positive and active performance at forum are considered to add scores in their usual performance.

\section{CONCLUSION}

In the course system of Food and Bioengineering Major, the biochemistry is more abstract than the other courses. It is hard to inspire the studying interest of students. If MOOC resource can be applied in the biochemistry teaching in a reasonable manner, which may play the role of pushing the teaching structure, teaching methods and even the reform of teaching thoughts, as well as the inspiration of studying interest for students. The innovative teaching method has raised one challenge to teachers and students. We should strive forward to solve difficulties, optimize MOOC teaching platform, improve the organization and arrange of face-to-face class and course communication channels, advocate the innovative forms of class notes, as well as continuously enhance the teaching quality of biochemistry course.

\section{REFERENCES}

[1] X.H. Hu, Y. Zhou, "Countermeasures of college teachers under the impact of the MOOC: a perspective of learning experience," Modern Educational Technology, 2014, vol. 24, pp. 19-25. (In Chinese)

[2] R. Yi, Y.Y. Qu, Q.H. Wang, L. Wu, X. Li, "Teaching exploration for biochemistry in the military medical university in the MOOC era," Chemistry of Life, 2017, vol. 37, pp. 660-664. (In Chinese)

[3] Y.G. Pan, S.Y. Li, "Practice and exploration of MOOC blended teaching method in food biochemistry course," Higher Agricultural Education, 2016, vol. 5, pp. 58-61. (In Chinese)

[4] Y. Huang, L. Ma, "Microlecture design of biochemistry under environment of Massive Open Online Course," Chinese Journal of Chemical Education, 2015, vol. 36, pp. 74-77. (In Chinese) 
[5] J.Y. Zhang, "A preliminary study on the reasons and Countermeasures of students' attention deficit concentration,” Examination weekly, 2010, vol. 1, pp. 224-225. (In Chinese)

[6] C.H. Huang, X.H. Yang, X.J. Hu, S. Tu, X.Y. Xiong, K.M. Jie,"How to activate the biochemistry class,” Chemistry of Life, 2018, vol. 38, pp. 156-159. (In Chinese)
[7] J. Zhang, “Advantage and Challenge of "MOOC + Flipped Classroom" Popularized in Colleges and Universities,” Education Teaching Forum, 2018, vol. 10, pp. 201-203. (In Chinese) 